\title{
The Effect of Hygrothermal Aging on the Glass and Carbon Reinforced Epoxy Composites for Different Stacking Sequences
}

\author{
Akar DOGAN****, Yusuf ARMAN*** \\ *Dokuz Eylül University, The Graduate School of Natural and Applied Sciences, Buca, Izmir, Turkey, \\ E-mail: akar.dogan@deu.edu.tr \\ **Munzur University, Department of Mechanical Engineering, Tunceli, Turkey, E-mail: akardogan@munzur.edu.tr \\ ***Dokuz Eylül University, Department of Mechanical Engineering, Buca, İzmir, Turkey, \\ E-mail: yusuf.arman@deu.edu.tr
}

crossref http://dx.doi.org/10.5755/j01.mech.24.1.18508

\section{Introduction}

Today, fiber-reinforced polymer (FRP) composites, thanks to their potential advantages such as highspecific strength, stiffness and being lightweight, have taken the place of traditional metals in many areas, such as automotive, aircraft industry, wind turbine, and marine applications. Despite the many advantages of polymer matrix composites compared to conventional metals, the biggest challenge is to ensure that they work with minimal external inspection and maintenance, especially over the years. For example, wind turbine blades or offshore structures that are difficult to monitor and maintain should be resistant to long-term humidity, cyclic temperatures, loads and UV radiations aging [1].

The durability of polymer matrix composite materials (PCMs) under environmental conditions has become an ongoing concern for the industry and researcher due to increasing use of polymer composite materials. In some application areas, environmental factors, such as heat, moisture, ultraviolet rays and loads may degrade the material properties $[2,3]$. In some applications, PCMs may be exposed to some hygrothermal conditions with high temperature and moisture content and this environment will lead to deterioration of composites properties $[4,5]$. Therefore, most researchers have focused on hygrothermal aging effects on PCMs [6-12]. Fitriah et al. [13] investigated the hygrothermal aging effects on crushing behaviour of glass fiber-reinforced epoxy pipes that were manufactured with three different winding angles by filament winding process. The pipes were then hydrothermally aged in tap water at a constant temperature of $80^{\circ} \mathrm{C}$ for periods of 500 , 1000 , and $1500 \mathrm{~h}$. They observed that at the end of the tests conducted, the strength of the pipes decreased with the waiting period. Hu et al. [1] reported that hygrothermal exposure affect matrix, fibers and interfaces in a different way. Carbon fibers are inert, while glass fibers are sensitive to humid environments.

Aging is generally divided into two classes, physical and chemical. Physical aging is the type of reversible aging involving both property and dimensional changes. On the other hand, in the case of chemical aging, there is irreversible degradation of the molecular structure caused by mechanisms such as chain scission, changes in crosslinking density and oxidation [14, 15]. During hygrothermal aging, additional cross-linking due to residual curing, secondary cross-linking between the polymer chains and the water molecules, swelling, micro-cracking, leaching of low molecular weight segments (decomposition), plasticization, polymer relaxation, etc. may occur [2, 16-20].

Polymers have several significant transition temperatures. The most important of these is the glass transition temperature $\left(T_{g}\right) . T_{g}$ may be the most important parameter that gives information about the aging of the material. During the hygrothermal aging process, an increase in $T_{g}$ may occur due to post-curing, while a decrease in $T_{g}$, modulus, and strength is based on plasticization and deterioration $[21,22]$. On the other hand, Alessi et al. [20] reported that moderate plasticization can increase fracture toughness by impeding propagation.

In this present study, effects of the hygrothermal aging behaviour of glass fiber and carbon fiber reinforced epoxy resin were compared. Vacuum-assisted resin infusion method was used to produce composite materials. Different from the literature review given above, hybrid composites were also investigated. It is well known that the carbon is more resistant to the humid environment than glass. However, the price of carbon is higher than glass. The aim of this study is to compare carbon and glass reinforced epoxy composites and the effects of stacking sequence on the mechanical properties of composites subjected to hygrothermal aging. The samples were exposed to a hygrothermal aging process for five weeks.

\section{Experimental procedure}

\subsection{Sample preparation}

The composite samples were produced by using vacuum-assisted resin infusion method. The areal density of the unidirectional glass fibre and carbon fibre fabric used was $300 \mathrm{~g} / \mathrm{m}^{2}$, respectively. A bicomponent Araldite LY 564 epoxy resin with an Aradur 3487 BD hardener was selected as a thermoset polymeric matrix. The mixing ratio of the epoxy to the hardener was $3: 1$ by weight. All the materials were packaged and the resin was infused under the vacuum as 1 bar. Curing was performed on a specially designed heating table at $50{ }^{\circ} \mathrm{C}$ for $30 \mathrm{~min}$ preheating and cured at $100^{\circ} \mathrm{C}$ for 2 hours, followed by cooling at room temperature. Four different composite materials, two of them hybrid, were fabricated by arranging carbon and Eglass fabrics with different stacking sequences symmetrically to the center. All composites materials consist of eight layers. The stacking sequences of composite materials are given in Fig. 1. Type A and B were produced using 
only glass and carbon reinforcement respectively, while type $\mathrm{C}$ and $\mathrm{D}$ were fabricated hybrid as shown schematically in Fig. 1. The thicknesses of samples for Type A, B, $\mathrm{C}$ and D were measured 2.1, 2,3, 2.25 and $2.25 \mathrm{~mm}$, respectively. In order to determine the mechanical properties, the test coupons were cut out from composite panels with a stacking sequence of [0] 8 according to ASTM D3039 [23] standard for tensile properties and ASTM D7264 [24] standard for flexural properties. The fiber volume fractions of all the plates were found as $57 \pm 3 \%$.

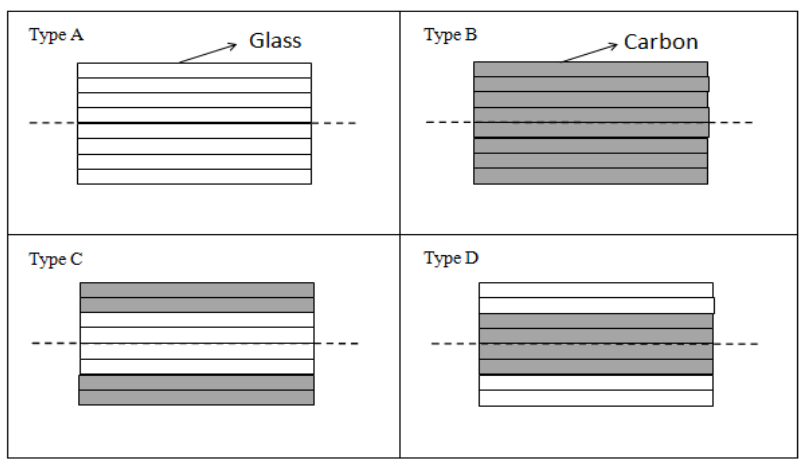

Fig. 1 Schematic view of stacking sequence of composite materials

\subsection{Hygrothermal aging process}

ATT Discovery DY110C climatic which allows conducting tests between $-70^{\circ} \mathrm{C}$ and $180^{\circ} \mathrm{C}$ and provides to control humidity at positive temperatures under $100^{\circ} \mathrm{C}$ was used to conducted aging process. The temperature and humidity values were respectively chosen as $90^{\circ} \mathrm{C}$ and $90 \%$. With 168 hours at each increment, test durations were increased gradually from 0 to 840 hours. A high selection of climate temperature was chosen because it is frequently used in the literature to accelerate aging in fiber reinforced polymers, especially during laboratory aging studies.

\subsection{Gravimetric measurement}

Before hygrothermal aging, the weight of five specimens $W_{0}$ (40mm x 40mm) for each type were measured and recorded. The samples were removed from the climatic cabin after aging durations of 100, 200, 300, 400, $500,600,840 \mathrm{~h}$, wiped dry with tissue paper and weighed by electronic scales. The moisture absorption content $\mathrm{Mt}$ is defined in Eq. (1) [2]:

$$
M_{t}(\%)=\frac{W_{t}-W_{0}}{W_{0}} \times 100,
$$

where: $W_{t}$ and $W_{0}$ are the specimen weights at time $t$ and initial state, respectively.

\subsection{Tensile tests}

For tensile testing, the tensile test specimens, which were of dimensions $15 \mathrm{mmx} 250 \mathrm{~mm}$ in the longitudinal direction and of dimensions $25 \mathrm{mmx} 175 \mathrm{~mm}$ in the transverse direction, were prepared from composite plates according to ASTM D3039. Shimadzu AG-X test machine having $100 \mathrm{kN}$ load capacity was used. Integrated video extensometer was used to measure the elongation of the specimens during the tensile test. From these tests, modulus of elasticity and tensile strengths in principal material directions were determined. The speed of crosshead was chosen as $1 \mathrm{~mm} / \mathrm{min}$. At least five tests were carried out for each type and duration times.

\subsection{Flexural property tests}

The three-point bending tests were conducted by the Shimadzu AG-X with a crosshead speed of $1 \mathrm{~mm} / \mathrm{min}$. The flexural test specimen's dimensions are $80 \mathrm{mmx} 12.7 \mathrm{~mm}$ and support span is $64 \mathrm{~mm}$. Similarly, in tensile tests, each test was repeated five times. The flexural strength $\sigma_{f}$ of the composites was calculated by Equation (2):

$$
\sigma=\frac{3 P L}{2 b d^{2}}
$$

where: $L, b, d$, and $P$ are the support span, specimen width, specimen depth, and flexural load, respectively.

\subsection{XPS analysis}

Surface chemistry of all samples was analyzed through X-ray photoelectron spectroscopy (XPS, Thermo Scientific) with monochromatic Al-K $\alpha(1486.7 \mathrm{eV}) \mathrm{X}$-ray source and a beam size of $400 \mathrm{~nm}$ diameter. The device was calibrated according to gold; 4f7/2. The vacuum pressure was below 10-9 Torr during spectra data acquisition. Survey XPS data were acquired to $1350 \mathrm{eV}$ from $-10 \mathrm{eV}$ with a pass energy of $150 \mathrm{eV}$ and a resolution of $1 \mathrm{eV} .20$ scans from a single point were recorded. The operation conditions were determined for a pass energy of $30 \mathrm{eV}$ and a resolution of $0.1 \mathrm{eV}$. Before operation surfaces of all samples were sputtered with ionic argon gas. Ar sputter cleaning was operated for $10 \mathrm{~s}$ (ion energy $=3 \mathrm{kV}$, primary current $=21 \mu \mathrm{A}$ ). Binding energies and atom concentration ratios were obtained using the curve fitting software [25].

\section{Result and discussion}

In this work, the effects of the combination of temperature and humidity on mechanical properties of Eglass/epoxy and carbon/epoxy composites were investigated experimentally.

Fig. 2 presents the percent weight change of the four different composite materials samples as a function of aging time. As shown, in the first 100 hours a linear and a rapid increase was observed in water absorption, then the sorption rate gradually slows down and reaches a saturated moisture level after a prolonged time. The saturated moisture content of Type A, B, C and D samples is $0.97 \%$, $0.95 \%, 1.01 \%$ and $0.88 \%$, respectively. The highest absorption was observed in Type $\mathrm{C}$, while the least in Type D. Glass and carbon fiber has a negligible quantity of water absorption, water uptake is mainly from water diffusion into microgaps between the polymer and fibre [26]. Yu and Yang [27] reported that moisture absorption of composites is highly affected especially when the matrix content is high in the interphase and void is an important factor in determining the water uptake of polymer-based composites. 


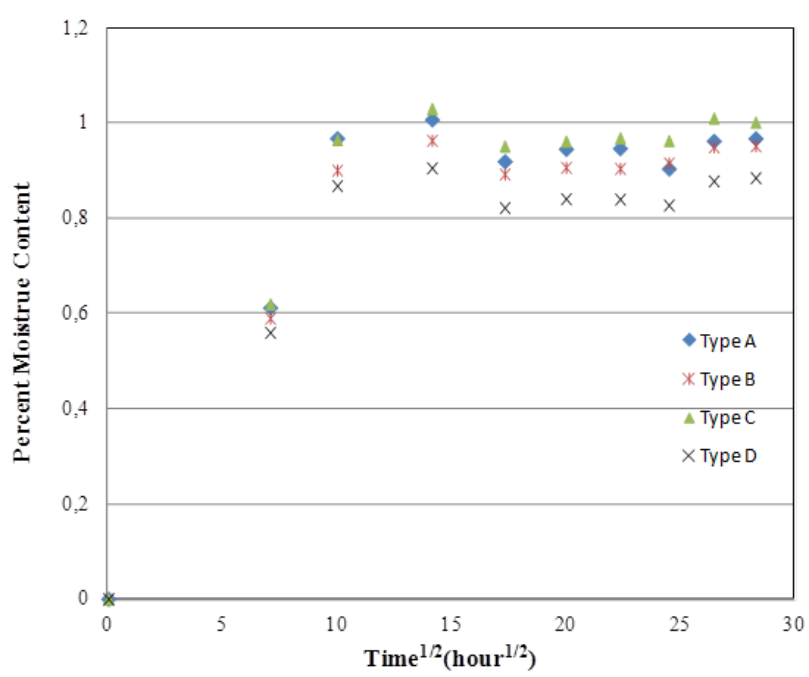

Fig. 2 Percent moisture content as a function of the square root of aging time for Type A, Type B, Type C and Type D composite samples

Stress-strain curves of the fiber direction at different aging times are shown in Fig. 3. As seen in the figures, the curves vary in an exactly linear fashion until rupture, due to the fact that the reinforcing material, namely glass fibre and carbon fibre are brittle materials and they dominate on the properties of composites in the fiber direction. It seems that, the failure stress and strain decrease with the increase of aging time for only glass reinforced epoxy composites (Type A). The failure elongation decreased by $30 \%$ for aging time of 5 weeks. That is, composite samples become more brittle as the aging time increases. However, in carbon and hybrid reinforced epoxy composite (Type B, C and D) no significant change has taken place. The slope of the curves implies the stiffness of specimens. The same behavior was observed for stiffness. In Fig. 4, variations of the tensile strength including standard deviation in fiber direction $\left(X_{\mathrm{t}}\right)$ versus aging time are given. In the first week, a sudden drop occurs in the tensile strength of Type A samples. After that time, relatively slower decline happened. The tensile strength of type A decreased $30 \%$ for an aging of 5 weeks. But, a slight increase was observed in the tensile strength for other types of samples. The postcuring process may have occurred.

The tensile strength in the transverse direction as a function of aging time is given in Fig. 5. The tensile strength decreases for all composites because in transverse direction matrix material dominates. In polymer composites, the matrix is one of the most exposed phases to environmental conditions [28]. The biggest decline occurred in Type B with approximately $40 \%$. Types C and D followed almost the same behavior. There was a rapid decline in transverse tensile strength after 1 week and it remains almost constant until 5 weeks. The same behavior occurred in water absorption as shown in Fig. 2. The penetration of water molecules to resin cause plasticization and deterioration of the resin, which causes the degradation of the tensile strength [2]. Yu and Yang [27] reported that hydrolysis leads to chain dissociation and segmentation. Therefore, the most water uptake occurred in the first week and this may have caused cracking and flaking of polymers.

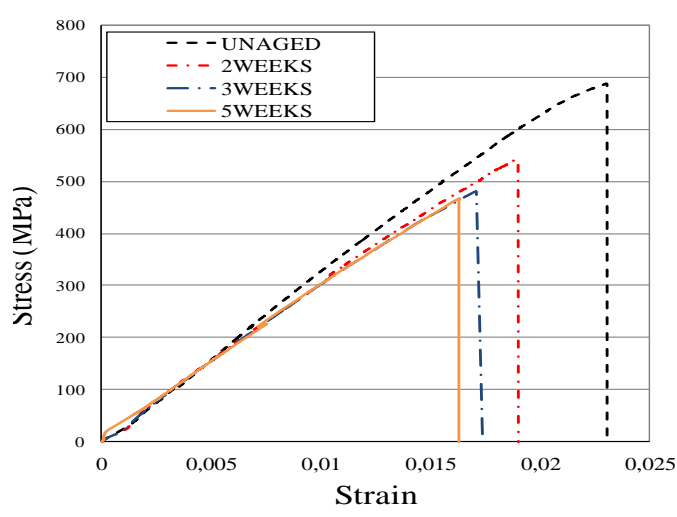

a

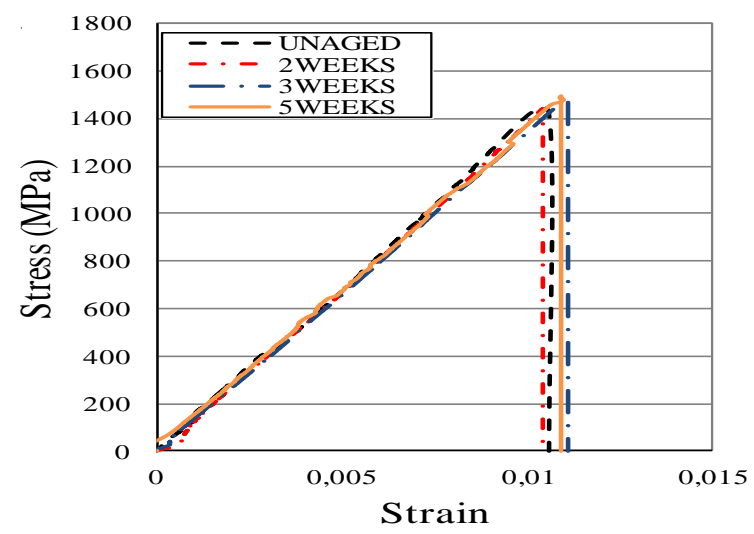

$\mathrm{b}$

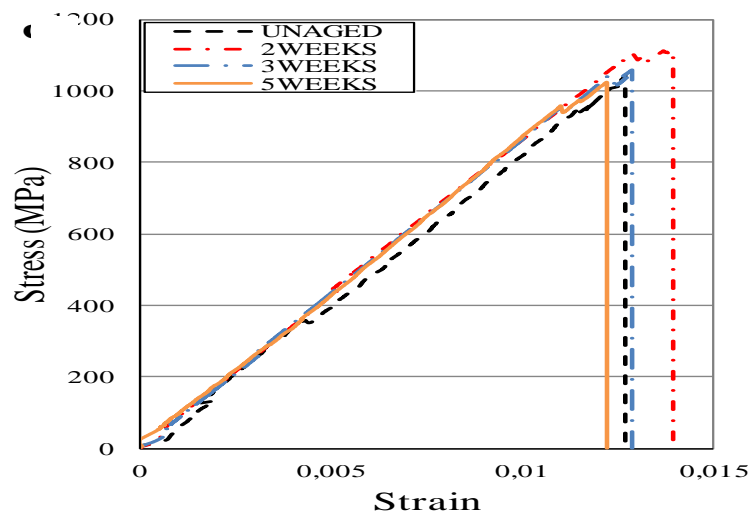

c

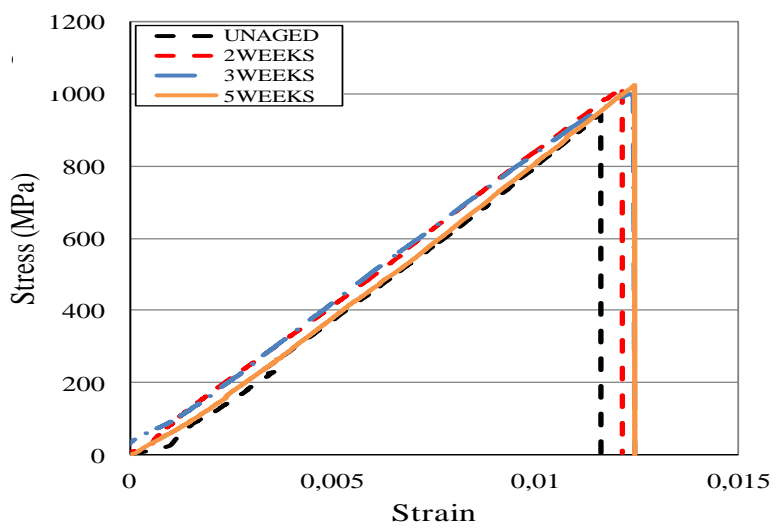

d

Fig. 3 Stress-strain curves of the samples for fiber direction at different aging times - a) Type A, b) Type B, c) Type C, d) Type D 


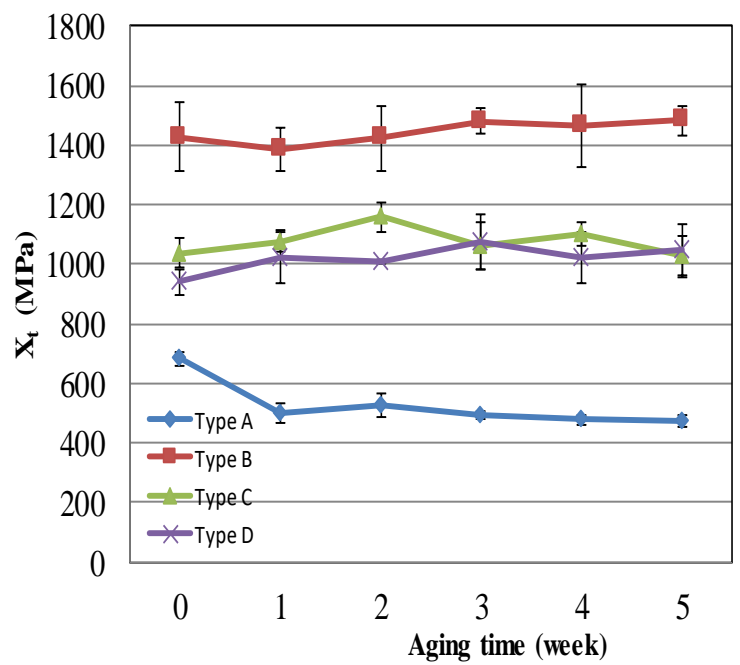

Fig. 4 Variation of the tensile strength in fiber direction versus aging time for four different samples

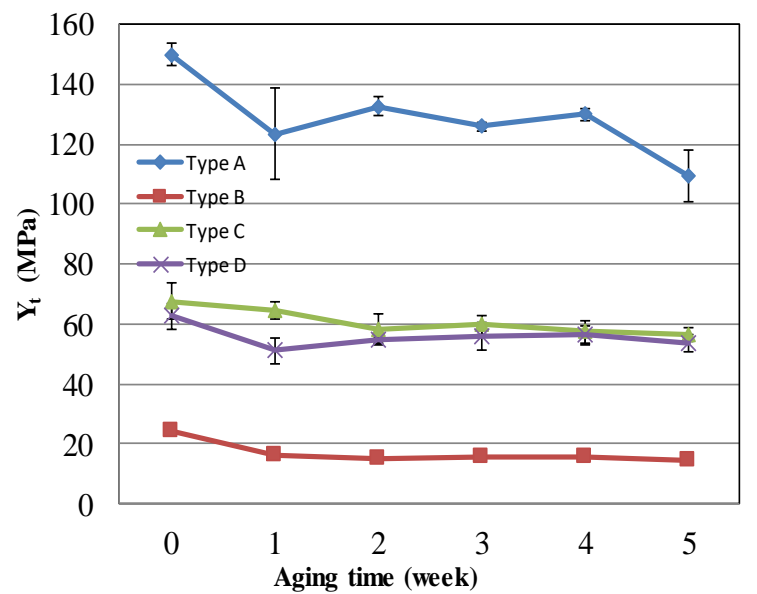

Fig. 5 Variation of the tensile strength in transverse direction versus aging time for four different samples

In Fig. 6, the stress-displacement curves of threepoint bending for all types of composites are presented with different aging times. The three-point bending stressdisplacement curves give valuable information about the elastic modulus. As shown in the figure, the slope of curves decreases with aging time, this implies a reduction in the flexural stiffness. Flexural strength of all composites was decreased with aging time, as shown in Fig 7. The greatest reduction occurred in Type D and it is almost $43 \%$. The highest stress occurs at the outermost layer during the bending stress and the E-glass is more sensitive to the humid environment compared to carbon. In type D, the outermost layer consists of glass fiber. Less reduction occurred in type B. As a result of mechanical tests, the highest reduction occurred in matrix-dominated properties such as the tensile strength in the transverse direction and flexural strength. The most common damage in laminated composites is matrix microcracking, which is transverse to the loading direction. Polymer composites are degraded faster than their components because the interphase between fiber and matrix plays a significant role in the properties of composites. The fiber /matrix interface is negatively affected by the water absorption at the interface [27].

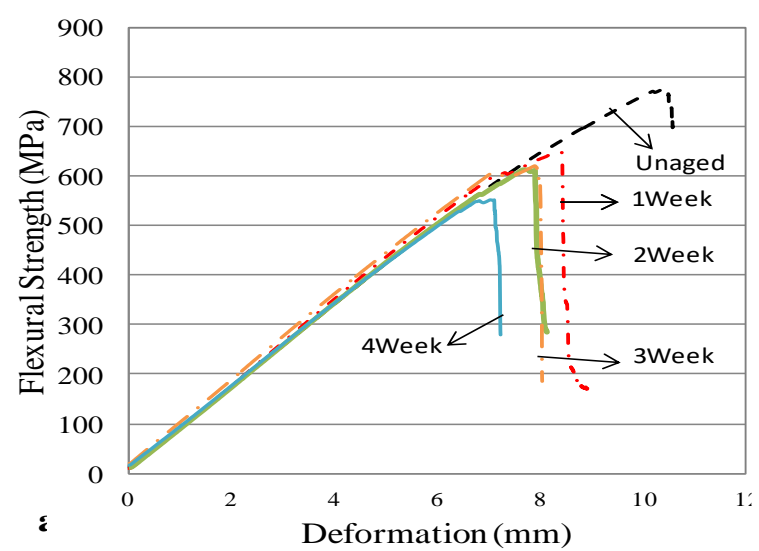

a

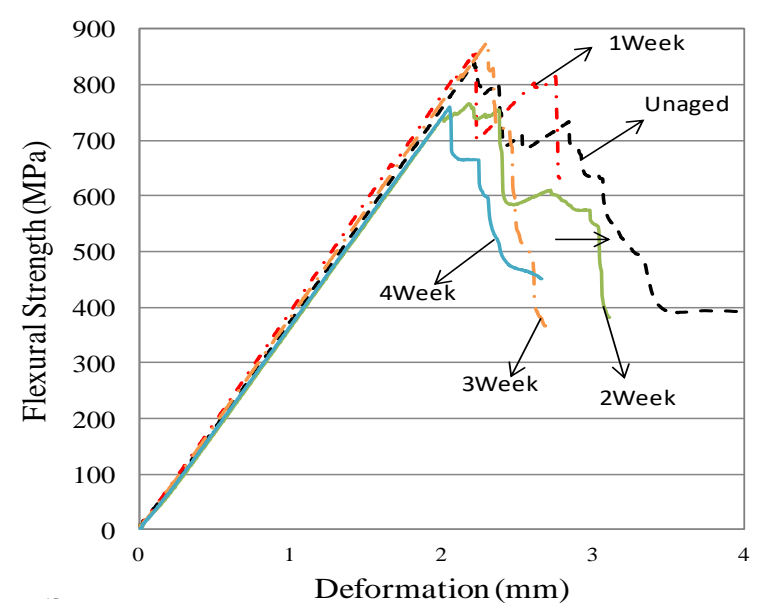

b

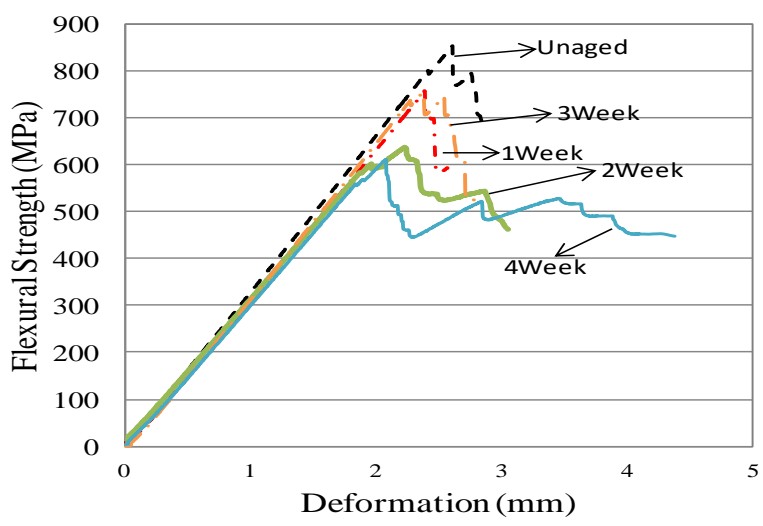

C

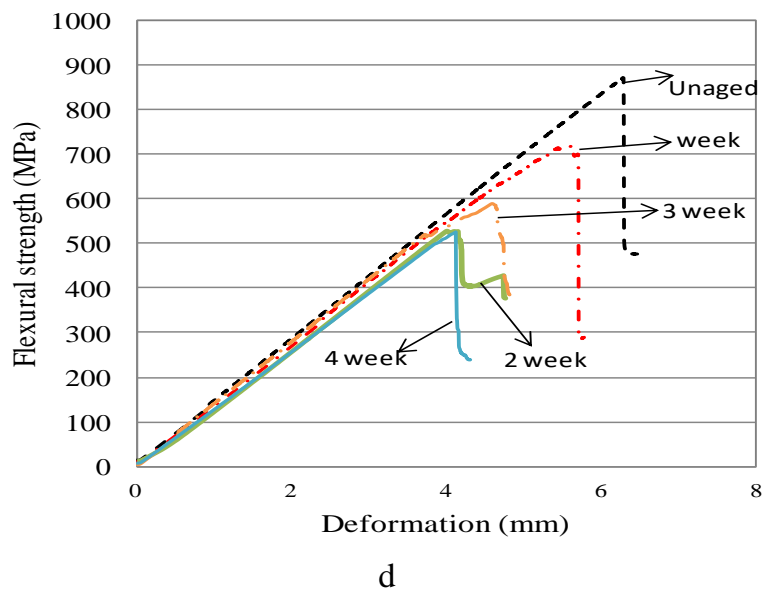

Fig. 6 Stress-strain curves of the samples for three-point bending test at different aging times 
Table 1

The relative atomic concentration of elements presents in the surface of composites after and before aging by XPS

\begin{tabular}{|c|c|c|c|c|c|c|}
\cline { 2 - 7 } \multicolumn{1}{c|}{} & \multicolumn{3}{c|}{ Carbon fibre reinforced samples } & \multicolumn{3}{c|}{ Glass fibre reinforced samples } \\
\cline { 2 - 7 } \multicolumn{1}{c|}{} & Uanged & 2 weeks aged & 4 weeks aged & Uanged & 2 weeks aged & 4 weeks aged \\
\hline $\mathrm{C}$ & 83.40 & 81.07 & 78.69 & 79.30 & 73.58 & 72.70 \\
\hline $\mathrm{O}$ & 12.01 & 13.03 & 15.36 & 13.58 & 18.06 & 18.59 \\
\hline $\mathrm{N}$ & 1.9 & 2.64 & 3.13 & 2.61 & 2.98 & 3.52 \\
\hline $\mathrm{Si}$ & 2.27 & 1.53 & 1.88 & 2.21 & 2.45 & 2.57 \\
\hline $\mathrm{Ca}$ & 1.34 & 1.01 & 0.68 & 0.50 & 1.21 & 1.44 \\
\hline $\mathrm{O} / \mathrm{C}$ & 0.144 & 0.160 & 0.195 & 0.171 & 0.245 & 0.255 \\
\hline
\end{tabular}

XPS was used to understand the distribution of atoms on the surface of specimens. The atomic concentration of elements in the surface for glass and carbon reinforced samples is given in Table1. The XPS analyses were carried out on samples un-aged, 2 and 4-weeks aged samples. Both the glass and carbon reinforced epoxy composite's surface oxygen content has increased. However, the carbon content of sample surface was decreased. Surface oxidation may be the dominant process for samples as a result of hygrothermal aging. Fan et al. [29] reported that the parts of carbon functional group were oxidized by $\mathrm{O} 2$

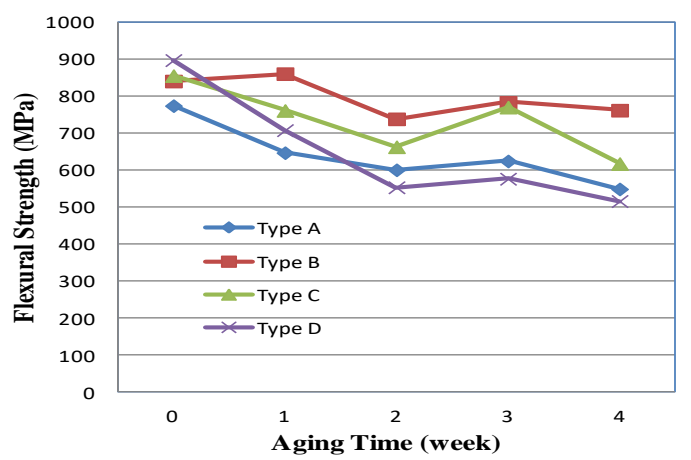

Fig. 7 Variation of the flexural strength in fiber directionversus aging time for four different samples

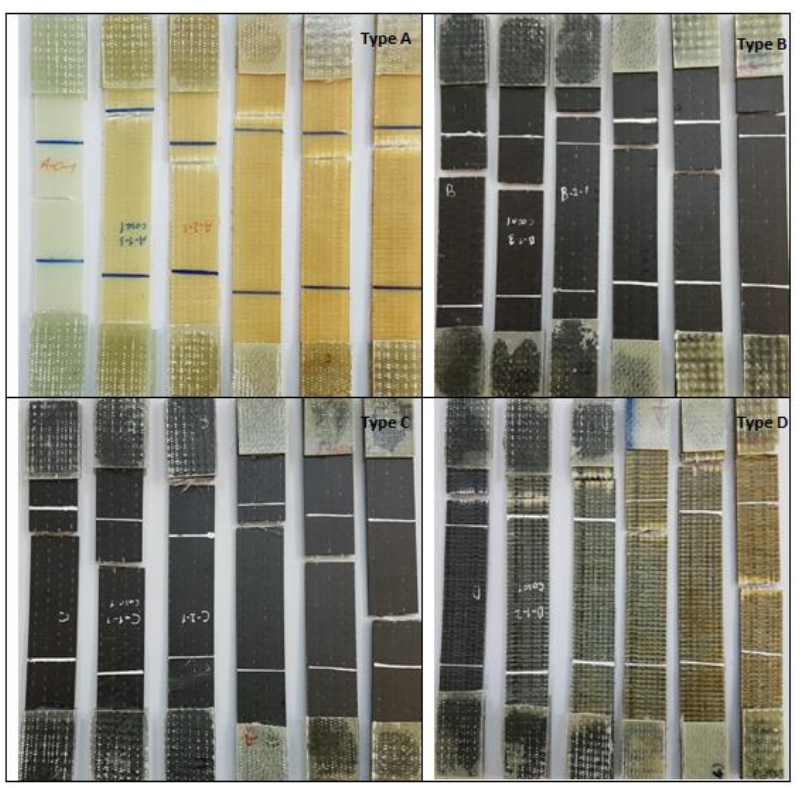

Fig. 8 Images of the damaged specimens subjected to tensile test for transverse direction or oxidation of the carbonyl species was likely to form $\mathrm{CO} 2$, resulting in increasing of $\mathrm{O}$ content and decreasing of the $\mathrm{C}$ content. The increase of $\mathrm{O} / \mathrm{C}$ ratio may indicate that epoxy resin gained oxygen through interactions with water molecular [30].

Images of the specimens subjected to tensile test are given in Fig. 8. From the figures, it is seen that the colors of specimens changed from light green to dark brown with aging time for type $\mathrm{A}$ and $\mathrm{D}$. On the other hand, there are no color change in the type B and C. It is proved that irreversible mechanism occurring during aging affected the optical properties of the glass reinforced composites. In addition to the surfaces, color change takes place through cross-sections of the samples which may be related to hydrolysis, and oxidation and hydrolysis affect whole the thickness [3].

\section{Conclusion}

This present work has studied the effect of hygrothermal aging on mechanical properties of epoxy resin composites that are reinforced with E-glass and carbon. The role of stacking sequence was also investigated. Tensile and three-point tests were conducted. Carbon and hybrid reinforced samples showed relatively good mechanical performance in tensile strength in fiber direction according to glass fibre reinforced samples. However, a significant decrease was observed for E-glass reinforced samples. Tensile strength in the transverse direction and flexural strength of all samples was decreased. All of the composites showed similar water uptake. Hygrothermal aging of PMCs is a major concern for structural durability in humid service environments. This work is expected to be helpful in understanding the effects of hygrothermal aging on the durability of epoxy resin.

\section{References}

1. Hu, Y.; Lang, A.W.; Li. X.; Nutt, S.R. 2014. Hygrothermal aging effects on fatigue of glass fiber/polydicyclopentadiene composites, Polymer degradation and stability, 110: 464-472.

https://dx.doi.org/10.1016/j.polymdegradstab.2014.10.0 18.

2. Wang, M.; Xu, X.; Ji, J.; Yang, Y.; Shen, J.; Ye, M. 2016. The hygrothermal aging process and mechanism of novolac epoxy resin, Composites Part B, 107: 1-8. https://dx.doi.org/10.1016/j.compositesb.2016.09.067.

3. Dogan, A.; Atas. C. 2016. Variation of the mechanical 
properties of E-glass/epoxy composites subjected to hygrothermal aging, Journal of composite materials, 50: 637-646.

https://dx.doi.org/10.1177/0021998315580451.

4. Yilmaz, T.; Sinmazcelik, T. 2010. Effects of hydrothermal aging on glass-fiber/polyetherimide (PEI) composites, Journal of Materials Science, 45: 399-404. https://dx.doi.org/10.1007/s10853-009-3954-1.

5. Karbhari, V.M.; Xian, G. 2009. Hygrothermal effects on high VF pultruded unidirectional carbon/epoxy composites: Moistureuptake, Composites Part B: Engineering, 40: 41-49.

https://dx.doi.org/10.1016/j.compositesb.2008.07.003.

6. Arif, M.F.; Meraghni, F.; Chemisky, Y.; Despringre, N.; Robert, G. 2014. In situ damage mechanisms investigation of pa66/gf30 composite: effect of relative humidity, Compostes Part B, 58: 487495.

https://dx.doi.org/10.1016/j.compositesb.2013.11.001.

7. Park, Y.; Kweon, J.; Choi, J. 2014. Failure characteristics of carbon/BMI-Nomex sandwich joints in various hygrothermal conditions, Composites Part B: Engineering, 60: 213-221.

https://dx.doi.org/10.1016/j.compositesb.2013.12.035.

8. Foulc, M.P.; Bergeret, A.; Ferry, L.; Ienny, P.; Crespy, A. 2005. Study of hygrothermal ageing of glass fibre reinforced PET composites, Polymer Degradation and Stability, 89: 461-470.

https://dx.doi.org/10.1016/j.polymdegradstab.2005.01.0 25.

9. Xin, H.; Liu, Y.; Mosallam, A.; Zhang. Y. 2016. Moisture diffusion and hygrothermal aging of pultruded glass fiber reinforced polymer laminates in bridge application, Composites Part B, Engineering. 100: 197207.

https://dx.doi.org/10.1016/j.compositesb.2016.04.085.

10. Sharma, N.; Kumar, M.S.; Ray, B.C. 2008. Study of the effect of hydrothermal ageing on glass/epoxy micro-composites by FTIR-imaging and alternating DSC techniques, J Reinf Plast Compos. 27: 1625-1634. https://dx.doi.org/10.1177/0731684407086318.

11. Vieille, J.; Aucher, J.; Taleb, L. 2012. Comparative study on the behavior of woven-ply reinforced thermoplastic or thermosetting laminates under severe environmental conditions, Mater Des., 35: 707-719. https://dx.doi.org/10.1016/j.matdes.2011.10.037.

12. Deroine, M.; Le Duigou, A.; Corre, Y.M.; et al. 2014. Accelerated ageing of polylactide in aqueous environments: comparative study between distilled water and seawater, Polym Degrad Stab., 108: 319-329.

https://dx.doi.org/10.1016/j.polymdegradstab.2014.01.0 20.

13. Fitriah, S.N.; Abdul Majid, M.S.; Ridzuan, M.J.M.; Daud, R.; Gibson, A.G.; Assaleh, T.A. 2017. Influence of hydrothermal ageing on the compressive behaviour of glass fibre/epoxy composite pipes, Composite Structure, 159: 350-360. https://dx.doi.org/10.1016/j.compstruct.2016.09.078.

14. Odegard, G.M.; Bandyopadhyay, A. 2011. Physical aging of epoxy polymers and their composites, Journal of Polymer Science Part B: Polymer Physics, 49: 16951716.

https://dx.doi.org/10.1002/polb.22384.

15. Martin R. 2008. Ageing of composites. Cambridge:
Woodhead Publishing Limited. Available from Internet:

https://www.elsevier.com/books/ageing-of-

composites/martin/978-1-84569-352-7.

16. Zhou, J.; Lucas. J.P. 1999. Hygrothermal effects of epoxy resin. Part II: variations of glass transition temperature, Polymer, 40(20): 5513-22.

https://dx.doi.org/10.1016/S0032-3861(98)00791-5.

17. Pochiraju, K.V.; Tandon, G.; Schoeppner, G.A. 2011. Long-term durability of polymeric matrix composites, Springer Science \& Business Media. Available from Internet:

https://www.springer.com/us/book/9781441993076.

18. Starkova, O.; Buschhorn, S.T.; Mannov, E.; Schulte, K.; Aniskevich, A. 2013. Water transport in epoxy/MWCNT composites, European Polymer Journal, 49(8): 2138-2148. https://dx.doi.org/10.1016/j.eurpolymj.2013.05.010.

19. Grammatikos, S.A.; Evernden, M.; Mitchels, J.; Zafari, B.; Mottram, J.T.; Papanicolaou, G.C. 2016. On the response to hygrothermal aging of pultruded FRPs used in the civil engineering sector, Materials and Desing. 96: 283-295.

https://dx.doi.org/10.1016/j.matdes.2016.02.026.

20. Alessi, S.; Conduruta, D.; Pitarresi, G.; Dispenza, C.; Spadaro. G. 2011. Accelerated ageing due to moisture absorption of thermally cured epoxy resin/polyethersulphone blends, Thermal, mechanical and morphological behaviour, Polymer Degradation and Stability, 96: 642-648.

https://dx.doi.org/10.1016/j.polymdegradstab.2010.12.0 27.

21. Firdosh, S.; Narasimha Murthy, H.N.; Pal, R.; Angadi G.; Raghavendra, N.; Krishna, M. 2015. Durability of GFRP nanocomposites subjected to hygrothermal ageing, Compos Part B: Engineering, 69: 443-45.

https://dx.doi.org/10.1016/j.compositesb.2014.09.028.

22. Davies, P.; Rajapakse, Y.D.S. 2014 Durability of Composites in a Marine Environment, London: Springer. Available from Internet:

https://www.springer.com/us/book/9789400774162. https://doi.org/10.1007/978-94-007-7417-9.

23. ASTM D3039/3039M-14, Standard Test Method for Tensile Properties of Polymer Matrix Composite Materials. ASTM International, West Conshohocken, Available from Internet:

https://www.astm.org/

24. ASTM D7264/7264M-15, Standard Test Method for Flexural Properties of Polymer Matrix Composite Materials. ASTM International, West Conshohocken, Available from Internet:

https://www.astm.org/

25. Yurddaskal, M.; Dikici, T.; Yildirim, S.; Yurddaskal M.; Toparli, M.; Celik, E. 2015. Fabrication and characterization of nanostructured anatase TiO2 films prepared by electrochemical anodization and their photocatalytic properties, Journal of Alloys and Compounds, 651: 59-71.

https://dx.doi.org/10.1016/j.jallcom.2015.08.064.

26. Li, Y.; Li, R.; Huang, L; Wang, K.; Huang, X. 2016. Effect of hygrothermal aging on the damage characteristics of carbon woven fabric/epoxy laminates subjected to simulated lightning strike, Materials and 
Design, 99: 477-489.

https://dx.doi.org/10.1016/j.matdes.2016.03.030.

27. Yu, B.; Yang, J. 2018. Hygrothermal Effects in Composites, Reference Module in Materials Science and Materials Engineering, 1:502-519. https://dx.doi.org/10.1016/B978-0-12-803581-8.098878.

28. Khan, L.A.; Mahmood, A.H.; Syed, A.S.; Khan, Z.M.; Day, R.J. 2013. Effect of hygrothermal conditioning on the fracture toughness of carbon/epoxy composites cured in autoclave/quickstep, Journal of Reinforced Plastics and Composites, 32: 1165-1176. https://dx.doi.org/10.1177/0731684413486367.

29. Fan, W.; Li, J.; Zheng, Y.; Liu, T.; Tian, X.; Sub, R. 2016. Influence of thermo-oxidative aging on the thermal conductivity of carbon fiber fabric reinforced epoxy composites, Polymer degradation and stability, 123: $162-169$. https://dx.doi.org/10.1016/j.polymdegradstab.2015.11.0 16.

30. Xiao, G.Z.; Delamar, M.; Shanahan, M.E.R. 1997. Irreversible interactions between water and DGEBA/DDA epoxy resin during hygrothermal aging, Journal of applied polymer science, 65: 449-458. https://dx.doi.org/10.1002/(SICI)10974628(19970718)65:3<449: AID-APP4>3.0.CO;2-H.
A. Dogan, Y. Arman

THE EFFECT OF HYGROTHERMAL AGING ON THE GLASS AND CARBON REINFORCED EPOXY COMPOSITES FOR DIFFERENT STACKING SEQUENCES

S u m m a r y

The present paper examines the effects of hygrothermal aging on the reinforced epoxy composites. The roles of reinforcement types and stacking sequence on the mechanical properties of composites under hygrothermal aging are investigated. Four different composite materials with different stacking sequence were produced. Unidirectional E-glass and carbon fabrics with an areal density $300 \mathrm{gr} / \mathrm{m}^{2}$ as reinforcement and epoxy as matrix were used. Composites were manufactured using vacuum-assisted resin infusion molding. In order to determine the mechanical properties of the composites, specimens were prepared according to the ASTM standards. The aging process was carried out in climatic test cabin at a temperature of $90^{\circ} \mathrm{C}$ and a humidity of $90 \%$. As a result of the tests, while the tensile strength of the glass reinforced composites decreased with aging time, no significant change was observed for carbon and hybrid composites. On the other hand, the tensile strength decreased in the transverse direction for all types of composites. XPS analysis was used to understand the distribution of atoms on the surface of specimens.

Keywords: glass and carbon fibers, epoxy, XPS, mechanical properties, hygrothermal aging.

Received July 02, 2017

Accepted February 15, 2018 